[Original article: 1 figure, 2 online tables, 1 online figure, 5 online videos ]

\title{
The expanding spectrum of movement disorders in genetic epilepsies
}

APOSTOLOS PAPANDREOU ${ }^{1,2 *}$

FEDERICA RACHELE DANTI ${ }^{1,3 *}$

ROBERT SPAULL ${ }^{4,5}$

VINCENZO LEUZZI ${ }^{3}$

AMY MCTAGUE 1,2

MANJU A KURIAN ${ }^{1,2}$

1 Molecular Neurosciences, Developmental Neurosciences Programme, UCL Great Ormond Street Institute of Child Health, London, UK; 2 Department of Neurology, Great Ormond Street Hospital, London, UK. 3 Department of Human Neuroscience, Unit of Child Neurology and Psychiatry, Sapienza University of Rome, Italy; 4 Department of Paediatric Neurology, Bristol Royal Hospital for Children, Bristol, UK. 5 Bristol Medical School, University of Bristol, Bristol, UK

Correspondence to Manju A Kurian, Molecular Neurosciences, Developmental Neurosciences Programme, UCL GOS Institute of Child Health, 30 Guildford Street, London, WC1N 1EH, UK. Email: manju.kurian@ucl.ac.uk

*These authors contributed equally to this work.

\section{PUBLICATION DATA}

Accepted for publication 01st March 2019.

Published online 29th November 2019. 


\section{ABBREVIATIONS}

AMPA $\quad \alpha$-amino-3-hydroxy-5-methyl-4-isoxazolepropionic acid

CSF Cerebrospinal fluid

EIMFS Epilepsy of infancy with migrating focal seizures

EOEE Early-onset epileptic encephalopathy

GABA Gamma-aminobutyric acid

GTCS Generalized tonic-clonic seizures

IEM Inborn errors of metabolism

LGS Lennox-Gastaut syndrome

NMDA N-methyl-D-aspartate

[Abstract]

An ever-increasing number of neurogenetic conditions presenting with both epilepsy and atypical movements are now recognized. These disorders within the 'genetic epilepsy-dyskinesia' spectrum are clinically and genetically heterogeneous. Increased clinical awareness is therefore necessary for a rational diagnostic approach. Furthermore, careful interpretation of genetic results is key to establishing the correct diagnosis and initiating disease-specific management strategies in a timely fashion. In this review we describe the spectrum of movement disorders associated with genetically determined epilepsies. We also propose diagnostic strategies and putative pathogenic mechanisms causing these complex syndromes associated with both seizures and atypical motor control.

[First page footer]

(c) Mac Keith Press

\section{DOI: $\underline{10.1111 / d m c n .14407}$}

[Left page footer]

Developmental Medicine \& Child Neurology 2019: XX: 000-000

[Right page footer]

Review 


\section{What this paper adds:}

- Implicated genes encode proteins with very diverse functions.

- Pathophysiological mechanisms by which epilepsy and movement disorder phenotypes manifest is often not clear.

- Early diagnosis of treatable disorders may require next generation genome sequencing.

[main text]

Recent advances have led to increased availability, reduced cost, and improved efficiency of nextgeneration sequencing technologies, thereby not only facilitating gene discovery for childhood epilepsy, but also enhancing the ability of clinicians to make diagnoses. This genomic revolution has however also muddied the diagnostic waters, and despite the development of robust consensus guidelines to determine mutation pathogenicity ${ }^{1}$ it can often be difficult to determine the true pathogenic relevance of identified genetic variants. Moreover, given the significant phenotypic pleiotropy and genetic heterogeneity observed in the genetic epilepsies, it is increasingly difficult to predict genotype from phenotype. ${ }^{2}$ As a consequence interpretation of genetic findings in clinical context can often be complex.

The development of improved clinical classification systems $^{3,4}$ has aided detailed phenotypic characterization of these genetic epilepsies, and it is now clear that the majority of these disorders are commonly associated with other neurological comorbidities including motor and cognitive delay, developmental regression, intellectual disability, neuropsychiatric features, and microcephaly. Furthermore, it is increasingly recognized that non-epileptic, atypical movements manifest in several genetic and neurometabolic syndromes which also feature epilepsy. ${ }^{5-12}$ The increasing availability of video-electroencephalogram (EEG) has facilitated differentiation of paroxysmal movements from epileptic seizures, thereby increasing clinical awareness of such epilepsy-dyskinesia phenotypes. 
In this review we report the spectrum of genetic disorders associated with epilepsymovement phenotypes, with a focus on the genetic epileptic encephalopathies where there are rarely biomarkers to aid genetic diagnosis. We describe the clinical presentation, disease course, electroclinical syndrome, and motor semiology observed. Although many patients with epilepsydyskinesia syndromes have complex neurodevelopmental syndromes with pyramidal signs, such as reduced axial tone and/or velocity-dependent spasticity, the focus of this review will be to better define the spectrum of extra-pyramidal movement disorders reported in epilepsy syndromes. Finally, we propose a diagnostic algorithm as a pragmatic tool to aid clinicians in the investigation of such conditions.

\section{EPILEPSY AND MOVEMENT DISORDERS IN INBORN ERRORS OF METABOLISM}

Many inborn errors of metabolism (IEM) can manifest with both epilepsy and atypical involuntary movements. ${ }^{13,14}$ A detailed description of such conditions is beyond the scope of this review; however, consideration in the differential diagnosis is crucial since targeted, disease-specific treatments are available for many of these disorders. An IEM may be suspected in patients with epilepsy born to consanguineous parents or with a family history of unexplained infantile deaths. IEM may be heralded by a number of suggestive clinical features including neonatal encephalopathy, neurological regression after a period of typical development, or clinical deterioration after intercurrent illness or starvation. ${ }^{15}$ In contrast to the genetic epilepsies, where there is a significant lack of reliable diagnostic biomarkers, biochemical and radiological features can often provide useful aids towards diagnosis of an IEM. For example, blood and urine testing can aid the diagnosis of specific lysosomal storage disorders, ${ }^{16}$ while serum transferrin isoelectric focusing is often atypical in congenital disorders of glycosylation. Congenital disorder of glycosylation type Is, caused by $A L G 13$ mutations, has been recently linked with West syndrome, ${ }^{17}$ choreoathetosis, and dyskinesia. ${ }^{18,19}$ Mitochondrial disorders, such as $P O L G$-related disease, can also often present with a combination of epilepsy and atypical movements. ${ }^{8,20}$ Here, diagnosis is often aided by characteristic brain magnetic resonance imaging (MRI) appearances as well as high 
plasma and cerebrospinal fluid (CSF) lactate levels. ${ }^{21}$ CSF studies are indeed key to diagnosing a number of IEM. A low fasting CSF to plasma glucose ratio is commonly detected in glucose transporter type 1 protein deficiency, due to mutations in $S L C 2 A 1$. Patients with glucose transporter type 1 protein deficiency present with a broad range of epileptic seizures including atonic, myoclonic, and generalized tonic-clonic seizures (GTCS); Reported movement disorders include ataxia, dystonia, chorea, and paroxysmal kinesigenic dyskinesia, paroxysmal non-kinesigenic dyskinesia, and paroxysmal exercise-induced dyskinesia. ${ }^{22,23}$ Severe depletion of CSF 5methyltetrahydrofolate is a classical feature of FOLRI-related disorders, ${ }^{24}$ where affected patients present with neurological regression and seizures (tonic, myoclonic, and myoclonic-astatic events), as well as ataxia, tremor, chorea, dystonia, and non-epileptic myoclonus. Primary neurotransmitter defects, which often lead to a combination of dyskinesias and epilepsy, can also be diagnosed by detection of specific CSF pterin and monoamine metabolite patterns. ${ }^{12}$

\section{EARLY ONSET EPILEPTIC ENCEPHALOPATHIES ASSOCIATED WITH MOVEMENT DISORDERS}

The early-onset epileptic encephalopathies (EOEEs) encompass a broad range of neurological disorders typically characterized by pharmacoresistant seizures and neurodevelopmental delay presenting in the neonatal period or infancy. EOEEs are clinically and genetically heterogeneous, which is attributed to a broad range of underlying aetiologies, including structural brain malformations, IEM, and single gene defects. ${ }^{4,25,26}$ Since the advent of next generation sequencing over 100 monogenic causes of EOEE have been reported, ${ }^{27}$ of which an increasing number are reported to result in epilepsy-dyskinesia phenotypes (Fig. 1, Table S1, online supporting information).

\section{Sodium channel genes}

Mutations in $S C N 2 A$, encoding the alpha-2 subunit of the voltage-gated sodium channel, are reported in EOEE syndromes such as Dravet syndrome, Ohtahara syndrome, West syndrome, and Lennox-Gastaut syndrome (LGS), epilepsy of infancy with migrating focal seizures (EIMFS), as 
well as in benign familial neonatal-infantile seizures and genetic epilepsy with febrile seizures plus. ${ }^{28,29}$ Severe hyperkinetic movement disorders, including dystonia and chorea, are often reported especially in neonatal-onset disease. Patients occasionally also manifest oculogyric crises, episodic ataxia, and prominent stereotypies in childhood. ${ }^{29,30}$

$S C N 8 A$, encoding another sodium channel subunit, has recently emerged as an important cause of EOEE, implicated in West syndrome, LGS, and Dravet syndrome, as well as benign familial neonatal-infantile seizures. Multiple seizure types are described including GTCS, tonic, focal (with or without impaired awareness), absence, and myoclonic seizures. ${ }^{31}$ Axial hypotonia is often present. Extrapyramidal features include dystonia, choreoathetosis, tremor, ataxia, and hand stereotypies. ${ }^{31,32}$ Additionally, episodic paroxysmal kinesigenic dyskinesia consisting of dystonic/hemi-dystonic, dyskinetic, or 'shivering' episodes have also been reported. ${ }^{33}$

The SCN1A-related phenotypic spectrum is broad and includes not only Dravet syndrome but also genetic epilepsy with febrile seizures plus, EIMFS, and infantile spasms. Recently, choreoathetosis, ballismus, dystonia, orofacial dyskinesia, hand stereotypies, and even familial cases of hemiplegic migraine have been described in patients with $S C N 1 A$-related disease. ${ }^{34-37}$ It has been reported that atypical movements are occasionally triggered by the sodium channel blockers phenytoin and carbamazepine. ${ }^{34,38}$ More recently, the c.677C>T; p.(Thr226Met) variant has been described in association with a distinct epilepsy-dyskinesia phenotype, more severe than Dravet syndrome, with a prominent hyperkinetic movement disorder. ${ }^{38}$

FHF1 encodes a voltage-gated sodium channel binding protein which modulates channel inactivation. Mutations in FHF1 (R52H), have been reported in patients with early onset epilepsy associated with progressive cerebellar atrophy and ataxia. ${ }^{39-41}$

\section{Potassium channel genes}

Autosomal dominant mutations in $K C N T 1$, which encodes the sodium-activated potassium channel, are identified in a wide range of epileptic disorders from benign familial neonatal-infantile seizures and autosomal dominant nocturnal frontal lobe epilepsy to severe EOEE syndromes, such as 
Ohtahara syndrome, West syndrome, and EIMFS. ${ }^{26,42}$ Axial hypotonia is frequently present though the majority of patients do not have other pyramidal tract signs. ${ }^{43}$ Moreover, some patients present with an early-onset choreiform movement disorder or generalized dystonia. ${ }^{26,43} K C N Q 2$, encoding the voltage-gated potassium channel (KQT-like subfamily), has been associated with benign familial neonatal-infantile seizures and more recently with EOEE, including Ohtahara syndrome, ${ }^{44}$ and West syndrome. ${ }^{45}$ Myokymia, myoclonus, ataxia, and dystonic posturing have all been described in affected patients. ${ }^{46-48}$ KCNBI mutations, affecting another voltage-gated potassium channel, have also been recently identified in patients with EOEE where hand-wringing stereotypies, chorea, and myoclonus have been reported. ${ }^{49}$

\section{Gamma-aminobutyric acid-related genes}

Mutations in genes encoding subunits of the gamma-aminobutyric acid (GABA) type A receptor are increasingly recognized in the epilepsy-dyskinesia spectrum. GABRAl mutations not only cause Dravet syndrome, Ohtahara syndrome, and West syndrome, but also juvenile myoclonic epilepsy, childhood absence epilepsy, and GTCS. Reported extrapyramidal features include myoclonus, dystonia, choreoathetosis, hand stereotypies, and bruxism. ${ }^{50}$ Recently a de novo GABRA2 mutation was found in a patient with EOEE, who also had severe hypotonia, and continuous choreiform movements. ${ }^{51}$ GABRB3 mutations, previously linked with Angelman syndrome, autism, and absence seizures, have recently been implicated in EOEE such as West syndrome and later onset epilepsy syndromes such as LGS and myoclonic atonic epilepsy. ${ }^{52,53}$ Hypotonia, ataxia, tremor, dyskinesia, and hand stereotypies are also often reported in affected patients. ${ }^{52}$ GABRG2 mutations cause Dravet syndrome, genetic epilepsy with febrile seizures plus, and also later-onset types such as childhood absence epilepsy, GTCS, and LGS. ${ }^{54,55}$ Here, patients also present with extrapyramidal features including choreoathetosis, ataxia, hand stereotypies, and atypical eye movements. Finally, mutations in $G A B R B 2$, recently identified in EOEE, ${ }^{56}$ also cause a 'MECP2-like' clinical phenotype ${ }^{57}$ consisting of neurological regression with developmental plateauing, hand stereotypies, autonomic dysfunction, sleep disturbance, microcephaly, and GTCS. Genotype-phenotype 
correlation suggests that mutations with greater impact on GABRB2 activity appear to cause the more severe EOEE phenotype. ${ }^{57}$ Related to GABA type A function, ARHGEF9 encodes a protein crucial for the formation of gephyrin and gephyrin-dependent GABA type A clusters in the postsynaptic membrane. Mutations in ARHGEF9 are reported in EOEE of variable seizure types (GTCS, tonic, focal with impaired awareness, and myoclonic seizures). Hyperekplexia and ataxia are described in some patients. ${ }^{58}$

\section{Genes in the N-methyl-D-aspartate pathway}

Mutations in GRIN2B (encoding the GluN2B subunit of the N-methyl-D-aspartate (NMDA) receptor) were first reported in patients with childhood-onset focal epilepsy, and more recently in patients with West syndrome. Severe hypotonia and dysphagia are described, with some patients also manifesting episodic axial hyperextension and dystonic finger movements. ${ }^{59-61}$ For patients with EOEE and GRIN2D mutations, affecting the GluN2D NMDA receptor subunit, hypotonia, choreoathetoid limb movements, paroxysmal extensor posturing, and involuntary eye movements resembling oculogyric crises have been reported. ${ }^{62}$ GRIN1 mutations impacting the GLuN1 subunit lead to multiple epilepsy phenotypes including infantile spasms, as well as focal with impaired awareness, generalized, and myoclonic seizures. ${ }^{63}$ Marked axial hypotonia, complex stereotypies, and a broad range of extrapyramidal features, such as fragmentary non-epileptic myoclonus, chorea, dyskinesia, and dystonia (that also affects eye movements and resembles oculogyric crises) are additional features in GRIN1-related disease. ${ }^{63-65}$

\section{Genes involved in synaptic vesicle dynamics}

Recessive mutations in $T B C 1 D 24$, encoding a protein involved in the regulation of synaptic vesicle trafficking, have been reported in patients with EIMFS and infantile spasms, as well as early onset myoclonic, febrile, clonic, tonic, GTCS, absence, and focal seizures. Affected patients often exhibit axial hypotonia and spasticity. Dystonia, ataxia, choreoathetosis, parkinsonism, and non-epileptic myoclonus are also reported. ${ }^{66,67}$ STXBP1 encodes a syntaxin-binding protein which plays a crucial role in neurotransmitter release from synaptic vesicles. Mutations of STXBP1 cause a wide range of 
EOEE disorders including Ohtahara syndrome, early myoclonic encephalopathy, and West syndrome. ${ }^{68}$ Pyramidal features, such as axial hypotonia and spasticity, and extra-pyramidal phenotypes, including ataxia, intention tremor, dyskinetic movements, and dystonia, are frequently seen in such patients. ${ }^{68-70}$ Furthermore, parkinsonian features have also been described in older patients. ${ }^{71}$ Stereotypies involving the hands, trunk, head, and neck, including the 'figure-of-eight' sequence, ${ }^{72}$ also feature in STXBP1-related disease. DNM1 encodes Dynamin-1, involved in synaptic and postsynaptic signalling. Mutations in this gene cause a neurodevelopmental disorder associated with West syndrome (often evolving to LGS) and choreiform hand movements, distal limb dystonia, ataxia, and tremor. ${ }^{60,73,74}$

\section{Genes encoding transporters}

Transportopathies are also increasingly recognized within the epilepsy-dyskinesia spectrum. Biallelic mutations in SLC13A5, encoding a high affinity sodium-dependent citrate transporter, are associated with EOEE, characterized by focal clonic seizures in the first week of life. The epilepsy tends to evolve into status epilepticus (hemiconvulsive, convulsive, and non-convulsive) and feversensitivity is frequently reported. Motor features including spasticity, ataxia, and choreoathetosis are often present. ${ }^{75,76}$ Finally, patients with SLC1A2 mutations, affecting the glutamate transporter EAAT2, manifest EOEE occasionally in tandem with movement disorders such as upper limb dyskinesia. ${ }^{77,78}$

\section{Genes with other cellular functions}

Biallelic mutations in $U B A 5$, a gene involved in protein posttranslational modification, cause EOEE including Ohtahara syndrome, West syndrome, or myoclonic jerks, and axial or peripheral hypotonia. Patients also often have pronounced dystonia and athetosis. ${ }^{79-81}$ Recessive mutations in $A R V 1$, encoding for an endoplasmic reticulum transmembrane protein, have also been identified in patients presenting with Ohtahara syndrome and dystonia/ataxia. ${ }^{82}$ Dystonic movements have been described in patients with EOEE (in particular West syndrome) due to mutations in SPTAN1, ${ }^{83,84}$ a gene involved in cytoskeleton organization. Mutations in this gene are associated with spastic 
quadriplegia and axial hypotonia, as well as dystonia and ataxia. ${ }^{83,84}$ Mutations in $Y W H A G$, encoding a member of the 14-3-3 protein family involved in intracellular signalling, protein trafficking, cell-cycle control, and apoptosis, ${ }^{77}$ cause EOEE characterized by variable seizure types (focal motor, GTCS, myoclonic, absence), ataxia, and tremor. AARS encodes for alanyl tRNA synthetase, an enzyme important in the initial phases of protein translation. Heterozygous AARS mutations are an established cause of dominantly inherited Charcot Marie Tooth disease type 2N; more recently, biallelic AARS mutations have been described in patients with severe EOEE, peripheral neuropathy, blepharospasm, orolingual dyskinesia, limb dystonia, and chorea. ${ }^{85,86}$

Additionally, patients with mutations in WWOX, a gene with a role in apoptosis and tumour suppression, ${ }^{87}$ present with treatment-resistant EOEE. Multiple seizure types are described, including infantile spasms, tonic, GTCS, and myoclonic seizures, while sometimes the electroclinical phenotype is compatible with LGS. Motor features include axial hypotonia, spasticity, cerebellar ataxia, and dystonia. ${ }^{87,88}$

INFANTILE-ONSET EPILEPTIC ENCEPHALOPATHIES ASSOCIATED WITH SEVERELY PROGRESSIVE MOVEMENT DISORDERS AND STATUS DYSTONICUS

Several conditions presenting with EOEE are associated with a markedly progressive, severe and disabling movement disorder.

$A R X$ encodes for a transcription factor with a pivotal role in the forebrain, pancreas, and testicular embryogenesis. ${ }^{89} A R X$ mutations are reported in a broad range of EOEE including Ohtahara syndrome, infantile spasms, and myoclonic seizures. ${ }^{89-91}$ Atypical motor semiology is often reported, with features of spasticity, as well as extra-pyramidal movement disorders such as progressive generalized dystonia, four limb dyskinesia, and non-epileptic myoclonic jerks. ${ }^{92}$ Status dystonicus has also been reported. ${ }^{91}$

Mutations in GNAOl, encoding the alpha-subunit of a heterotrimeric G protein implicated in the modulation of synaptic transmission, ${ }^{93}$ result in early onset epilepsy syndromes, such as EOEE, Ohtahara syndrome, and EIMFS-like phenotypes. Prominent movement disorders such as chorea, 
dystonia, facial, and orolingual dyskinesia and complex stereotypies are very commonly reported. ${ }^{93-95}$ Many affected patients present with progressive, potentially life-threatening episodic exacerbations, which often necessitate hospitalization in an intensive care setting. During periods of exacerbation atypical facial movements, orolingual dyskinesia, and complex stereotypies are also reported. ${ }^{93,95,96}$ Lasting from minutes to days or even months such exacerbations are commonly triggered by infection, pyrexia, heightened emotion, stress, and anxiety. Moreover, dysautonomic manifestations, such as tachycardia, hyperthermia, hypertension, and diaphoresis, are often described..$^{93,95,96}$

\section{CHILDHOOD-ONSET GENETIC EPILEPSY SYNDROMES WITH MOVEMENT}

\section{DISORDERS}

\section{Potassium channel genes}

KCNA2-related epilepsy presents with childhood-onset epilepsy of multiple seizure types including GTCS, myoclonic, and absence seizures. Patients also manifest ataxia and tremor, 4-limb dystonia, midline hand stereotypies, and myoclonic movements. ${ }^{97-99}$ Moreover, autosomal recessive $K C N J 10$ mutations cause epilepsy, ataxia, sensorineural deafness, and tubulopathy syndrome. Patients present with infantile-onset GTCS, ${ }^{100-102}$ while non-progressive ataxia is evident from the first year of life. Finally, KCND3 mutations, traditionally linked with ataxia, cognitive impairment, tremor, myoclonus, and neuropathy (Spinocerebellar Ataxia 19/22), have also been described in patients with parkinsonian features, dysarthria, dysphagia, and childhood/adult-onset generalized or focal seizures with impaired awareness. ${ }^{103}$

\section{a-amino-3-hydroxy-5-methyl-4-isoxazolepropionic acid receptors}

Mutations in GRIA4, which encodes an $\alpha$-amino-3-hydroxy-5-methyl-4-isoxazolepropionic acid (AMPA) receptor subunit (GluR4) found on excitatory glutamatergic synapses, cause a spectrum of phenotypes from an early infancy or childhood onset neurodevelopmental disorder (with or without seizures and a clumsy or stiff gait) to EOEE with intractable seizures in the first weeks of life. Spastic quadriplegia, choreiform, and stereotypic hand movements and ataxia are also reported. ${ }^{104}$ 
Recently, mutations in FRRSIL, which encodes an important component of the outer core of the AMPA receptor accessory proteins, were identified in patients with childhood onset epilepsy associated with regression of skills, choreoathetosis, dystonia, and, later on in life, rigidity and hypokinesia. ${ }^{105}$ Seizure types included multifocal, GTCS, and tonic, while some patients evolve into LGS.

\section{Genes encoding transporters}

Mutations in genes leading to aberrant function of cellular transporters can also present with childhood-onset epilepsy and movement disorders. SLC6Al encodes one of the major brain transporters of GABA; mutations lead to childhood-onset myoclonic-atonic epilepsy as well as autistic features, stereotypies, ataxia, and tremor. ${ }^{106}$ Mutations in the $S L C 9 A 6$ gene, which encodes a sodium-hydrogen exchanger, cause Christianson syndrome, an X-linked intellectual disability syndrome. Some children present with phenotypes reminiscent of Angelman syndrome, ${ }^{107}$ characterized by intellectual disability, early-onset epilepsy, ataxia with progressive cerebellar atrophy, and progressive neurological dysfunction associated with tau-deposition. ${ }^{108}$

\section{Genes involved in degradation/turnove $r$ of intracellular and extracellular components}

Deficient expression of the maternal copy of the $U B E 3 A$ gene, encoding a protein involved in the ubiquitin/proteasome system, leads to Angelman syndrome. Phenotypic features include intellectual disability, speech impairment, epilepsy (with a characteristic EEG pattern and multiple seizure types typically presenting in childhood), and a behavioural profile of hyperexcitability, happy demeanour, and frequent laughter. Additionally, patients with Angelman syndrome also exhibit jerkiness, ataxia, tremor, mouthing of objects, stereotypies, ${ }^{109}$ and, towards adolescence or adulthood, non-epileptic myoclonus. ${ }^{110}$ Mutations in a gene encoding a protein with similar function (HACE1), were also recently found to cause neurodevelopmental delay and childhood onset epilepsy characterized by GTCS, myoclonic, and focal seizures, with hypotonia, lower limb spasticity, ataxia, and dystonia. ${ }^{111,112}$ HACE1 not only functions as an E3 ubiquitin ligase but also represses the transcriptional activity of retinoic acid receptors and, hence, downstream pathways 
that are involved in a range of cellular processes including neuronal differentiation/regeneration and stimulation of neurite outgrowth. ${ }^{111}$

Defects in autophagy, another innate cellular system of cargo disposal and recycling, also lead to mixed epilepsy/movement disorder phenotypes. Mutations in WDR45 cause beta-propeller protein-associated neurodegeneration, a subtype of neurodegeneration with brain iron accumulation. Beta-propeller protein-associated neurodegeneration manifests with epilepsy of multiple seizure types (febrile, focal with impaired awareness, absences, atonic, tonic, epileptic spasms, GTCS, and myoclonic, or even EOEE or West syndrome), ${ }^{113}$ MECP2-like hand wringing stereotypies, and, later in the disease course, neurological regression, dystonia, and prominent parkinsonian features. ${ }^{114}$ EPG5 mutations lead to Vici syndrome, a multisystemic condition encompassing seizures, which are often severe and can present as EOEE or LGS, as well as atypical motor semiology including dystonia and choreoathetosis. ${ }^{115}$ More recently, mutations in another autophagy gene, SNX14, have been found to cause delayed development, hypotonia, absent speech, progressive cerebellar atrophy, ataxia, and seizures. ${ }^{116}$

DNAJC6 has recently been added to the expanding spectrum of genes causing later-onset epilepsy-dyskinesia. DNAJC6 encodes the brain-specific isoform of auxilin, a protein with a wellestablished role in clathrin-mediated endocytosis and synaptic vesicle recycling. Prominent tremor, bradykinesia, rigidity, and dystonia commonly starts in childhood or early adolescence. Some patients also have epilepsy characterized by generalized EEG discharges, the onset of which can either occur before ${ }^{117}$ or after ${ }^{118}$ the parkinsonian features manifest clinically. Psychiatric features including hallucinations, sometimes linked to levodopa administration, have also been reported. ${ }^{117-}$ 119

\section{Genes involved in postsynaptic cell signalling}

GNB1 mutations have been recently identified in patients with childhood or adolescence-onset epilepsy, neurodevelopmental delay, tics, hypotonia, dystonia, ataxia, and intermittent actioninduced myoclonus. ${ }^{120-122} \mathrm{G} \beta 1$ is the $\beta$-subunit of a guanine nucleotide-binding protein that forms 
heterotrimeric complexes with $G$ protein subunits $\alpha$ and $\gamma . G \beta 1$ is involved in the same cellular pathway as GNAOI (Section 3) and interacts with GNAL (encoded by the gene mutated in DYT25 dystonia), ${ }^{121}$ which might provide a causative link to the combined epilepsy and movement disorder phenotype seen in these patients.

In addition, mutations in SYNGAP1, which encodes a protein that constitutes a downstream component of the NMDA receptor-associated signalling complex, have been shown to cause epilepsy and atypical movements. ${ }^{123}$ Affected patients present with late infantile-onset seizures, drop attacks, myoclonic jerks, atonic seizures, myoclonic absences, or absences, in tandem with hypotonia and ataxia.

\section{THE PROGRESSIVE MYOCLONIC EPILEPSIES}

The progressive myoclonic epilepsies are a genetically and clinically heterogeneous group of disorders characterized by epilepsy of varying degrees, and associated with neurological decline with ataxia and dementia. ${ }^{124}$ Metabolic aetiologies, such as neuronal ceroid lipofuscinoses, ${ }^{125}$ are well recognized in progressive myoclonic epilepsies, but many other genetic causes have also been described including mutations in CSTB (Unverricht-Lundborg disease), EPM2A (Lafora disease), GOSR2, KCNC1, PRICKLE1, SCARB2, and KCTD7. ${ }^{126-131}$ These genes encode proteins with a wide variety of cellular functions, such as intracellular trafficking (GOSR2), ${ }^{132}$ lysosomal function (SCARB2), and sodium channels (KCNC1). Stimulus-sensitive or action myoclonus (with and without EEG correlate), ataxia, and tonic-clonic seizures are consistent features in all progressive myoclonic epilepsies, while significant associated dementia is encountered in some subtypes (e.g. Lafora disease and neuronal ceroid lipofuscinoses). ${ }^{127}$ Muscle biopsies often have characteristic appearances and prove useful when investigating or suspecting such disorders. ${ }^{125}$

\section{EPILEPSY SYNDROMES ASSOCIATED WITH PROMINENT STEREOTYPIES}

Mutations in $M E C P 2$, encoding a transcription factor highly expressed in the brain, cause a neurodevelopmental disorder historically known as Rett syndrome. After a period of typical development, neurological regression (including loss of purposeful hand skills and language) and 
postnatal microcephaly ensue. Epilepsy of multiple seizure types, focal with impaired awareness, absence, atonic, tonic, GTCS, myoclonic, occurs in the majority of cases. Movement disorders, including ataxia, dystonia, chorea, myoclonus, tremor, rigidity, hand stereotypies typically involving the midline, ${ }^{133}$ can be prominent with hyperkinetic movements more common in younger patients and parkinsonian features in older ones. ${ }^{133,134}$

FOXG1 mutations share some overlapping features with MECP2-related disease. The encoded protein is also a transcription factor involved in fetal telencephalic development and postmitotic neuron survival. ${ }^{134}$ Unlike the $M E C P 2 \mathrm{X}$-linked inheritance pattern (and consequential female predominance) both sexes are relatively equally affected. FOXG1-related disease is characterized by global neurodevelopmental delay, rather than neurological regression, often accompanied by poor feeding, irritability, hypotonia, postnatal microcephaly, lack of purposeful hand use, and visual inattention. Epilepsy with multiple seizure types including GTCS, myoclonic, and focal seizures with impaired awareness presents in infancy, often as EOEE and/or infantile spasms, or as childhood-onset epilepsy. ${ }^{108,135}$ Hyperkinetic movement disorders are a cardinal and important disease feature with a combination of choreoathetosis, dystonia, myoclonus, orolingual dyskinesia, and distinct (mainly unilateral) hand stereotypies being present in all patients, even in the absence of epilepsy. Dystonia-parkinsonism is reported in older patients. ${ }^{134}$

Mutations in CDKL5, which is involved in transcriptional regulation/DNA modification and repair, are also associated with a clinical phenotype encompassing both epilepsy and atypical motor stereotypies. Similarly to $M E C P 2$ there is $\mathrm{X}$-linked inheritance with most patients being female. Postnatal microcephaly and poor purposeful hand use are key disease features. Epileptic seizures of early onset often include EOEE, infantile spasms, myoclonic seizures, and prolonged GTCS (although less severe forms have also been described), while atypical movements mainly consist of hand stereotypies and bruxism, ${ }^{5}$ ataxia, chorea, dystonia, and myoclonus. ${ }^{18,136}$

PCDH19 mutations, which encodes a protein highly expressed in the brain, important for cell-cell adhesion, axon guidance, and dendrite self-avoidance, ${ }^{137}$ are well known to lead to EOEE 
and later-onset epilepsy in females, characterized by focal and/or generalized seizures that typically occur in clusters. Other associations also include autistic features and behavioural issues, sleep disturbance, and hand stereotypies. ${ }^{138}$

Dystonia, dyskinesia, chorea, MECP2-like features, and hand stereotypies in childhood are described in patients with $M E F 2 C$ mutations, who also manifest EOEE and childhood-onset epilepsy including myoclonic, atonic seizures, and infantile spasms. ${ }^{139}$

Similar to $M E C P 2$, a number of genes causing epilepsy syndromes with prominent stereotypies encode for transcription factors, or proteins involved in transcriptional regulation. First, HNRNPU encodes a protein that facilitates interactions between genes, mRNA, and proteins during mRNA processing thereby regulating gene expression. ${ }^{140}$ Mutations in the gene cause EOEE (including infantile spasms, West syndrome, and LGS) and childhood-onset epilepsy with seizures initially occurring in the context of febrile episodes. ${ }^{140-142}$ Neurological regression is reported in some patients, and hand-flapping stereotypies appear to be a common feature. TBL1XR1 also encodes a protein that localizes to the nucleus and plays a role in transcription mediated by nuclear receptors. ${ }^{143}$ Mutations are associated with West syndrome, hand stereotypies, developmental delay, and autistic or MECP2-like features. ${ }^{18,144}$ Moreover, PURA mutations, a gene encoding a protein with multiple regulatory functions in processes like DNA replication, transcription, mRNA transport, DNA repair, and a role in neuronal development and differentiation, have recently been described in PURA syndrome. ${ }^{145}$ The condition is multisystemic with central nervous system involvement including several seizure types: GTCS, focal, absence, tonic seizures, infantile spasms, drop attacks, and, over time, evolution to LGS. Atypical motor features include hypotonia, spasticity, MECP2-like stereotypies, chorea, dystonia, and ataxia. ${ }^{145}$ Loss of function mutations in SMC1A, with a role in chromosome segregation during cell division, cause drug-resistant tonic seizures or GTCS often occurring in clusters, infantile spasms, and EIMFS, and psychomotor regression. Patients also manifest hypotonia, spasticity, and midline hand wringing stereotypies. ${ }^{146-}$ ${ }^{150}$ Finally, SETD5, which encodes for a methyltransferase enzyme highly expressed in the brain, ${ }^{151}$ 
was initially described in association with intellectual disability and dysmorphic features, gastrointestinal malformations, and behavioural problems including obsessive-compulsive or autistic features as well as stereotypical hand flapping. ${ }^{151}$ Mutations were also recently identified in patients with West syndrome with, again, associated hand stereotypes. ${ }^{18}$

Genes with regulatory roles in synaptic activity have also been linked with MECP2-like phenotypes. First, mutations in IQSEC2 are associated with regression, stereotypical hand movements, spasticity, postnatal microcephaly, and epilepsy, including EOEE, atypical absences, and infantile spasms phenotypes. ${ }^{152,153}$ IQSEC2 has an essential role in modulating the cytoskeleton and vesicle transport at the postsynaptic density and hence is a crucial modifier of synaptic plasticity. ${ }^{153}$ Interestingly, IQSEC2 escapes X-inactivation in females and the phenotype can therefore be related to the severity of loss-of-function, as in autosomal genes. ${ }^{154} A P 3 B 2$ encodes the neuronal-specific subunit of a protein mediating the sorting and transport of vesicle membrane proteins between the neuronal cell body and nerve terminus. ${ }^{155}$ AP3B2 mutations are now reported in EOEE characterized by infantile spasms, tonic-clonic, and tonic seizures. Patients also exhibit axial hypotonia and atypical movements such as midline hand stereotypies, dystonia, and chorea. ${ }^{155}$

Choreoathetosis ${ }^{156}$ and stereotypies ${ }^{157}$ have been described in patients with recessive SZT2 mutations presenting with EOEE. SZT2 regulates the mechanistic target of rapamycin complex 1 signalling pathway, ${ }^{158}$ malfunction of which is implicated in several central nervous system developmental abnormalities. ${ }^{159}$

Finally, stereotypies are increasingly recognized as a feature in other genetic disorders including WDR45-, GRIN1-, and GABRB2-related epilepsy; these have all been described in previous sections. ${ }^{56,63,114}$

\section{PARKINSONISM IN CHILDHOOD-ONSET GENETIC EPILEPSIES}

Paediatric movement disorders are mainly hyperkinetic. Hypokinetic movement disorders are less commonly described, encountered more frequently in older patients. This is exemplified by patients with MECP2 mutations, where early disease is characterized by hyperkinetic movements, and 
parkinsonian features manifest later on in the disease course. ${ }^{133}$ Similarly, mutations in other epilepsy-related genes (KCND3, STXBP1, DNAJC6, FOXG1, WDR45, FRRS1L, TBC1D24, ATP1A3) can cause hypokinesia and parkinsonism, ${ }^{66,71,105,114,117,133,134,160}$ usually manifesting later in childhood, adolescence, or adulthood.

\section{PAROXYSMAL DYSKINESIAS AND EPILEPSY}

Paroxysmal dyskinesias are characterized by the episodic occurrence of involuntary extrapyramidal movements. Based on the precipitating factor, these can be subdivided into three clinical syndromes: paroxysmal kinesigenic dyskinesia, paroxysmal non-kinesigenic dyskinesia, and paroxysmal exercise-induced dyskinesia. ${ }^{23,35}$ They are often associated with epilepsy, manifesting in patients with mutations in genes encoding synaptic proteins/receptors (PRRT2, CHRNA4), ion channels (KCNA1, KCNMA1, SCN8A, CACNA1A), and transporters (SLC2A1, SLC16A2, ATP1A2, ATP1A3). ${ }^{161}$

The clinical features of paroxysmal kinesigenic dyskinesia, paroxysmal non-kinesigenic dyskinesia, and other paroxysmal dyskinesias are detailed in Table 1. In the context of epilepsy, paroxysmal kinesigenic dyskinesia is reported in patients harbouring mutations in PRRT2, ${ }^{162,163}$ SCN8A, ${ }^{31,33}$ SLC16A2,164,165 and CHRNA4. ${ }^{166}$ Additionally, epilepsy occurs in tandem with paroxysmal non-kinesigenic dyskinesia in $C A C N A 1 A^{167}$ and $K C N M A 1$-related disease, ${ }^{168-170}$ while paroxysmal exercise-induced dyskinesia is often described in cases of SLC2A1-related glucose transporter type 1 protein deficiency. ${ }^{23}$ Other paroxysmal movement disorders include hemiplegic migraine and the episodic ataxias. CACNA1A, SCN1A, and ATP1A2 mutations are mainly responsible for co-occurrence of familial hemiplegic migraine and epilepsy, ${ }^{35,171}$ while a combination of episodic ataxias and epileptic seizures is reported in PRRT2, ${ }^{23,163} C A C N A 1 A,{ }^{167}$ and KCNA1 $1^{35,172,173}$ mutation-positive patients. ${ }^{34,174}$ Finally, ATP1A3 mutations manifest in a broad clinical spectrum encompassing alternating hemiplegia of childhood, rapid-onset dystoniaparkinsonism, and epilepsy. ${ }^{35,175}$

\section{A DIAGNOSTIC APPROACH}


Approaching the epilepsy-dyskinesia spectrum from a diagnostic perspective can be challenging in view of the clinical and genetic heterogeneity, non-specific or atypical presentations, and lack of clinical awareness of rarer entities. Clinicians should therefore have a low threshold for referring such complex cases to appropriate specialist clinics, where available.

Thorough history taking and clinical examination is paramount, while the use of mobile phones and/or video capturing (either in hospital or at home) is useful, especially in the case of paroxysmal movement disorders. Detailed neuroimaging should also be considered early on not only for potential diagnostic clues but also to exclude structural abnormalities that could explain the constellation of symptoms and signs.

Additionally, IEM should always be considered, and where appropriate sufficiently excluded, with an important emphasis on searching for treatable conditions. A combination of atypical motor semiology and epilepsy is frequently encountered in many metabolic conditions. ${ }^{7}$ Hence, relevant investigations should be initiated as required, depending on the clinical presentation.

For neurogenetic conditions presenting with movement disorders and epilepsy accurate electroclinical characterization of the epileptic events and phenotypic delineation of the atypical motor semiology will enable more targeted biochemical, radiological, and neurophysiological investigations and subsequent genetic testing. Even in the era of next generation sequencing such clinical characterization will aid the interpretation of genetic data, especially for genetic variants of unknown significance.

Microarray-based comparative genomic hybridization should be a first-line genetic investigation, as copy number variants encompassing key gene(s) may indeed be responsible for the observed clinical phenotypes. The diagnostic yield from microarray is reported to be significant for both epilepsy $\mathrm{y}^{27}$ and movement disorders. ${ }^{176}$ Next generation sequencing approaches such as gene panels and whole exome or genome sequencing are now usually second line genetic investigations. Rarely, targeted single gene testing may be undertaken in cases of high clinical or biochemical 
suspicion; this should be initiated early on in the diagnostic process. Conversely, more invasive investigations such as tissue biopsies are often expensive and of comparatively low yield ${ }^{177,178}$ and could, therefore, be considered ever further down the investigative process. A suggested diagnostic algorithm is summarized in Figure S1 (online supporting information).

\section{PUTATIVE PATHOGENIC MECHANISMS}

Intriguingly, similar clinical phenotypes encompassing both epilepsy and movement disorders are caused by an ever-expanding compendium of genes, encoding for proteins with very diverse functions (Fig. 1, Table S2 online supporting information). The exact mechanism through which this occurs is unclear, but it is likely to be multifactorial. It is plausible that the affected protein functions may be ubiquitous and/or indispensable throughout the central nervous system. For example, genes involved in toxic cargo removal or recycling are likely to be of key importance in non-regenerating, postmitotic neurons. Hence, mutations in genes such as WDR45, EPG5, SNX14, $U B E 3 A$, or $H A C E 1,{ }^{109,111,116}$ might lead to broad cellular dysfunction in multiple neuronal subtypes, which, in turn, would clinically manifest as a combination of neurological features, including epileptic seizures and motor abnormalities. Additionally, genes involved in synaptic function (neurotransmission, synaptic vesicle cycle, G-protein-coupled signal transduction) would also be predicted to affect multiple neuronal subtypes within both cortical and subcortical networks, hence leading to a complex clinical picture with epilepsy and motor defects. Finally, genetic epilepsydyskinesia may be attributed to genes that either cause radiologically discernible structural brain abnormalities or preferentially affect specific parts of the brain involved in motor control and coordination. For example, FOXG1 mutations lead to both forebrain underdevelopment and atypical basal ganglia gene expression. ${ }^{134}$ Beta-propeller protein-associated neurodegeneration (due to WDR45 mutations) preferentially affect the substantia nigra and globus pallidus, as evident on brain magnetic resonance imaging ${ }^{114}$ and neuropathology studies. ${ }^{179}$ Moreover, some genes (for instance SPTAN1, ${ }^{83}$ SLC9A6, ${ }^{107}$ and $\left.S N X 14\right)^{116}$ are associated with cerebellar atrophy, which may impact key corticothalamic pathways and other important motor networks, thereby leading to both epilepsy 
and a movement disorder.

\section{CONCLUSIONS}

Our review summarizes the 'genetic epilepsy-dyskinesia' spectrum and describes a genetically and clinically heterogeneous group of conditions caused by mutations in genes encoding proteins with a diverse set of neuronal functions. These disorders are often under-recognized, mainly because of their rarity and heterogeneity, and, therefore, delays in diagnosis and appropriate management are common. This issue is becoming increasingly relevant, with a number of promising disease-specific treatments either already available or currently being developed in preclinical studies and clinical trials. ${ }^{180-182}$ With the advent of next generation sequencing and enhanced clinical phenotyping, it is likely that the genetic epilepsy-dyskinesia spectrum will further expand. Clinical awareness is paramount, to achieve a more focused diagnostic approach. Robust interpretation of genetic data will facilitate accurate prognostication and genetic counselling. Ultimately establishing the exact underlying molecular defect will lead to initiation of appropriate management strategies, and more precision medicine approaches in the future.

\section{Acknowledgements}

The authors have stated that they had no interests that might be perceived as posing a conflict or bias.

\section{Supporting information}

The following additional material may be found online:

Table S1: Summary of clinical manifestations in epilepsy-dyskinesia disorders

Table S2: Function of genes implicated in the genetic epilepsy-dyskinesia spectrum

Figure S1: Proposed diagnostic approach for children presenting with epilepsy and movement disorders.

Video S1-5: Videos demonstrating movement phenotypes in patients with mutations to GNAO1, FOXG1, KCNA2, IQSEC2, and SCN2A. 


\section{REFERENCES}

1. Richards S, Aziz N, Bale S, et al. Standards and guidelines for the interpretation of sequence variants: a joint consensus recommendation of the American College of Medical Genetics and Genomics and the Association for Molecular Pathology. Genet Med 2015; 17: 405-24.

2. McTague A, Howell KB, Cross JH, Kurian MA, Scheffer IE. The genetic landscape of the epileptic encephalopathies of infancy and childhood. Lancet Neurol 2016; 15: 304-16.

3. Sanger TD, Chen D, Fehlings DL, et al. Definition and classification of hyperkinetic movements in childhood. Mov Disord 2010; 25: 1538-49.

4. Berg AT, Berkovic SF, Brodie MJ, et al. Revised terminology and concepts for organization of seizures and epilepsies: report of the ILAE Commission on Classification and Terminology, 20052009. Epilepsia 2010; 51: 676-85.

5. Guerrini R, Parrini E. Epilepsy in Rett syndrome, and CDKL5- and FOXG1-gene-related encephalopathies. Epilepsia 2012; 53: 2067-78.

6. Wisniewski KE, Zhong N, Philippart M. Pheno/genotypic correlations of neuronal ceroid lipofuscinoses. Neurology 2001; 57: 576-81.

7. Eggink H, Kuiper A, Peall KJ, et al. Rare inborn errors of metabolism with movement disorders: a case study to evaluate the impact upon quality of life and adaptive functioning. Orphanet J Rare Dis 2014; 9: 177.

8. Martikainen MH, Ng YS, Gorman GS, et al. Clinical, genetic, and radiological features of extrapyramidal movement disorders in mitochondrial disease. JAMA Neurol 2016; 73: 668-74.

9. Papandreou A, Gissen P. Diagnostic workup and management of patients with suspected Niemann-Pick type C disease. Ther Adv Neurol Disord 2016; 9: 216-29.

10. Sechi A, Deroma L, Dardis A, et al. Long term effects of enzyme replacement therapy in an Italian cohort of type 3 Gaucher patients. Mol Genet Metab 2014; 113: $213-8$.

11. Mercimek-Mahmutoglu S, Stoeckler-Ipsiroglu S, Adami A, et al. GAMT deficiency: features, treatment, and outcome in an inborn error of creatine synthesis. Neurology 2006; 67: 480-4.

12. Ng J, Papandreou A, Heales SJ, Kurian MA. Monoamine neurotransmitter disorders -clinical advances and future perspectives. Nat Rev Neurol 2015; 11: 567-84.

13. García-Cazorla A, Wolf NI, Serrano M, et al. Inborn errors of metabolism and motor disturbances in children. J Inherit Metab Dis 2009; 32: 618-29.

14. Gouider-Khouja N, Kraoua I, Benrhouma H, Fraj N, Rouissi A. Movement disorders in neurometabolic diseases. Eur J Paediatr Neurol 2010; 14: 304-7.

15. Sharma S, Prasad AN. Inborn errors of metabolism and epilepsy: current understanding, diagnosis, and treatment approaches. Int J Mol Sci 2017; 18: 1384.

16. Filocamo M, Morrone A. Lysosomal storage disorders: molecular basis and laboratory testing. Hum Genomics 2011; 5: 156-69.

17. Allen AS, Berkovic SF, Cossette P, et al. De novo mutations in epileptic encephalopathies.

Nature 2013; 501: 217-21.

18. Kobayashi $Y$, Tohyama J, Kato M, et al. High prevalence of genetic alterations in early-onset epileptic encephalopathies associated with infantile movement disorders. Brain Dev 2016; 38: $285-$ 92.

19. Galama WH, Verhaagen-van den Akker SLJ, Lefeber DJ, Feenstra I, Verrips A. ALG13-CDG with infantile spasms in a male patient due to a de novo ALG13 gene mutation. JIMD Rep 2018;

40: $11-6$.

20. Synofzik M, Schule R, Schulte C, et al. Complex hyperkinetic movement disorders associated with POLG mutations. Mov Disord 2010; 25: 2472-5.

21. Wolf NI, Rahman S, Schmitt B, et al. Status epilepticus in children with Alpers' disease caused by POLG1 mutations: EEG and MRI features. Epilepsia 2009; 50: 1596-607.

22. Leen WG, Klepper J, Verbeek MM, et al. Glucose transporter-1 deficiency syndrome: the expanding clinical and genetic spectrum of a treatable disorder. Brain 2010; 133: 655-70. 
23. Gardiner AR, Jaffer F, Dale RC, et al. The clinical and genetic heterogeneity of paroxysmal dyskinesias. Brain 2015; 138: 3567-80.

24. Pérez-Dueñas B, Toma C, Ormazábal A, et al. Progressive ataxia and myoclonic epilepsy in a patient with a homozygous mutation in the FOLR1 gene. J Inherit Metab Dis 2010; 33: 795-802. 25. Mastrangelo M, Leuzzi V. Genes of early-onset epileptic encephalopathies: from genotype to phenotype. Pediatr Neurol 2012; 46: 24-31.

26. McTague A, Appleton R, Avula S, et al. Migrating partial seizures of infancy: expansion of the electroclinical, radiological and pathological disease spectrum. Brain 2013; 136: 1578-91.

27. Mercimek-Mahmutoglu S, Patel J, Cordeiro D, et al. Diagnostic yield of genetic testing in epileptic encephalopathy in childhood. Epilepsia 2015; 56: 707-16.

28. Shi X, Yasumoto S, Kurahashi H, et al. Clinical spectrum of SCN2A mutations. Brain Dev 2012; 34: 541-5.

29. Howell KB, McMahon JM, Carvill GL, et al. SCN2A encephalopathy: a major cause of epilepsy of infancy with migrating focal seizures. Neurology 2015; 85: 958-66.

30. Liang JS, Lin LJ, Yang MT, Wang JS, Lu JF. The therapeutic implication of a novel SCN2A mutation associated early-onset epileptic encephalopathy with Rett-like features. Brain Dev 2017; 39: $877-81$.

31. Larsen J, Carvill GL, Gardella E, et al. The phenotypic spectrum of SCN8A encephalopathy. Neurology 2015; 84: 480-9.

32. Bagnasco I, Dassi P, Blé R, Vigliano P. A relatively mild phenotype associated with mutation of SCN8A. Seizure 2018; 56: 47-9.

33. Gardella E, Becker F, Møller RS, et al. Benign infantile seizures and paroxysmal dyskinesia caused by an SCN8A mutation. Ann Neurol 2016; 79: 428-36.

34. Ohtsuka Y, Ohmori I, Ogino T, Ouchida M, Shimizu K, Oka E. Paroxysmal movement disorders in severe myoclonic epilepsy in infancy. Brain Dev 2003; 25: 401-5.

35. Silveira-Moriyama L, Kovac S, Kurian MA, et al. Phenotypes, genotypes, and the management of paroxysmal movement disorders. Dev Med Child Neurol 2018; 60: 559-65.

36. Ohashi T, Akasaka N, Kobayashi Y, et al. Infantile epileptic encephalopathy with a hyperkinetic movement disorder and hand stereotypies associated with a novel SCN1A mutation. Epileptic Disord 2014; 16: 208-12.

37. Dichgans M, Freilinger T, Eckstein G, et al. Mutation in the neuronal voltage-gated sodium channel SCN1A in familial hemiplegic migraine. Lancet 2005; 366: 371-7.

38. Sadleir LG, Mountier EI, Gill D, et al. Not all SCN1A epileptic encephalopathies are Dravet syndrome: early profound Thr226Met phenotype. Neurology 2017; 89: 1035-42.

39. Siekierska A, Isrie M, Liu Y, et al. Gain-of-function FHF1 mutation causes early-onset epileptic encephalopathy with cerebellar atrophy. Neurology 2016; 86: 2162-70.

40. Guella I, Huh L, McKenzie MB, et al. De novo FGF12 mutation in 2 patients with neonatalonset epilepsy. Neurol Genet 2016; 2: e120.

41. Al-Mehmadi S, Splitt M, Ramesh V, et al. FHF1 (FGF12) epileptic encephalopathy. Neurol Genet 2016; 2: e115.

42. Heron SE, Smith KR, Bahlo M, et al. Missense mutations in the sodium-gated potassium channel gene KCNT1 cause severe autosomal dominant nocturnal frontal lobe epilepsy. Nat Genet 2012; 44: 1188-90.

43. McTague A, Nair U, Malhotra S, et al. Clinical and molecular characterization of KCNT1related severe early-onset epilepsy. Neurology 2018; 90: e55-e66.

44. Saitsu H, Kato M, Koide A, et al. Whole exome sequencing identifies KCNQ2 mutations in Ohtahara syndrome. Ann Neurol 2012; 72: 298-300.

45. Kato M, Yamagata T, Kubota M, et al. Clinical spectrum of early onset epileptic encephalopathies caused by KCNQ2 mutation. Epilepsia 2013; 54: 1282-7.

46. Weckhuysen S, Ivanovic V, Hendrickx R, et al. Extending the KCNQ2 encephalopathy spectrum: clinical and neuroimaging findings in 17 patients. Neurology 2013; 81: 1697-703. 
47. Dedek K, Kunath B, Kananura C, Reuner U, Jentsch TJ, Steinlein OK. Myokymia and neonatal epilepsy caused by a mutation in the voltage sensor of the KCNQ2 K+ channel. Proc Natl Acad Sci U S A 2001; 98: 12272-7.

48. Blumkin L, Suls A, Deconinck T, et al. Neonatal seizures associated with a severe neonatal myoclonus like dyskinesia due to a familial KCNQ2 gene mutation. Eur J Paediatr Neurol 2012; 16: $356-60$.

49. Saitsu H, Akita T, Tohyama J, et al. De novo KCNB1 mutations in infantile epilepsy inhibit repetitive neuronal firing. Sci Rep 2015; 5: 15199.

50. Kodera H, Ohba C, Kato M, et al. De novo GABRA1 mutations in Ohtahara and West syndromes. Epilepsia 2016; 57: 566-73.

51. Orenstein N, Goldberg-Stern $H$, Straussberg R, et al. A de novo GABRA2 missense mutation in severe early-onset epileptic encephalopathy with a choreiform movement disorder. Eur J Paediatr Neurol 2018; 22: 516-24.

52. Møller RS, Wuttke TV, Helbig I, et al. Mutations in GABRB3: from febrile seizures to epileptic encephalopathies. Neurology 2017; 88: 483-92.

53. Papandreou A, McTague A, Trump N, et al. GABRB3 mutations: a new and emerging cause of early infantile epileptic encephalopathy. Dev Med Child Neurol 2016; 58: 416-20.

54. Shen D, Hernandez CC, Shen W, et al. De novo GABRG2 mutations associated with epileptic encephalopathies. Brain 2017; 140: 49-67.

55. Kang JQ, Macdonald RL. Molecular pathogenic basis for GABRG2 mutations associated with a spectrum of epilepsy syndromes, from generalized absence epilepsy to Dravet syndrome. JAMA Neurol 2016; 73: 1009-16.

56. Ishii A, Kang JQ, Schornak CC, et al. A de novo missense mutation of GABRB 2 causes early myoclonic encephalopathy. J Med Genet 2017; 54: 202-11.

57. Yoo Y, Jung J, Lee YN, et al. GABBR2 mutations determine phenotype in rett syndrome and epileptic encephalopathy. Ann Neurol 2017; 82: 466-78.

58. Alber M, Kalscheuer VM, Marco E, et al. ARHGEF9 disease: Phenotype clarification and genotype-phenotype correlation. Neurol Genet 2017; 3: e148.

59. Lemke JR, Hendrickx R, Geider K, et al. GRIN2B mutations in West syndrome and intellectual disability with focal epilepsy. Ann Neurol 2014; 75: 147-54.

60. Allen NM, Conroy J, Shahwan A, et al. Unexplained early onset epileptic encephalopathy: Exome screening and phenotype expansion. Epilepsia 2016; 57: e12-7.

61. Platzer K, Yuan H, Schütz H, et al. GRIN2B encephalopathy: novel findings on phenotype, variant clustering, functional consequences and treatment aspects. J Med Genet 2017; 54: 460-70.

62. Li D, Yuan H, Ortiz-Gonzalez XR, et al. GRIN2D Recurrent de novo dominant mutation causes a severe epileptic encephalopathy treatable with NMDA receptor channel blockers. Am J Hum Genet 2016; 99: 802-16.

63. Ohba C, Shiina M, Tohyama J, et al. GRIN1 mutations cause encephalopathy with infantileonset epilepsy, and hyperkinetic and stereotyped movement disorders. Epilepsia 2015; 56: 841-8. 64. Lemke JR, Geider K, Helbig KL, et al. Delineating the GRIN1 phenotypic spectrum: a distinct genetic NMDA receptor encephalopathy. Neurology 2016; 86: 2171-8.

65. Zehavi Y, Mandel H, Zehavi A, et al. De novo GRIN1 mutations: an emerging cause of severe early infantile encephalopathy. Eur J Med Genet 2017; 60:317-20.

66. Balestrini S, Milh M, Castiglioni C, et al. TBC1D24 genotype-phenotype correlation: Epilepsies and other neurologic features. Neurology 2016; 87: 77-85.

67. Doummar D, Mignot C, Apartis E, et al. A novel homozygous TBC1D24 mutation causing multifocal myoclonus with cerebellar involvement. Mov Disord 2015; 30: 1431-2.

68. Stamberger H, Nikanorova M, Willemsen MH, et al. STXBP1 encephalopathy: a neurodevelopmental disorder including epilepsy. Neurology 2016; 86: 954-62.

69. Deprez L, Weckhuysen S, Holmgren P, et al. Clinical spectrum of early-onset epileptic encephalopathies associated with STXBP1 mutations. Neurology 2010; 75: 1159-65. 
70. Carecchio M, Mencacci NE. Emerging monogenic complex hyperkinetic disorders. Curr Neurol Neurosci Rep 2017; 17: 97.

71. Keogh MJ, Daud D, Pyle A, et al. A novel de novo STXBP1 mutation is associated with mitochondrial complex I deficiency and late-onset juvenile-onset parkinsonism. Neurogenetics 2015; 16: 65-7.

72. Kim YO, Korff CM, Villaluz MM, et al. Head stereotypies in STXBP1 encephalopathy. Dev Med Child Neurol 2013; 55: 769-72.

73. Nakashima M, Kouga T, Lourenço CM, et al. De novo DNM1 mutations in two cases of epileptic encephalopathy. Epilepsia 2016; 57: e18-23.

74. von Spiczak S, Helbig KL, Shinde DN, et al. DNM1 encephalopathy: a new disease of vesicle fission. Neurology 2017; 89: 385-94.

75. Thevenon J, Milh M, Feillet F, et al. Mutations in SLC13A5 cause autosomal-recessive epileptic encephalopathy with seizure onset in the first days of life. Am J Hum Genet 2014; 95: 113-20.

76. Hardies K, de Kovel CG, Weckhuysen S, et al. Recessive mutations in SLC13A5 result in a loss of citrate transport and cause neonatal epilepsy, developmental delay and teeth hypoplasia. Brain 2015; 138: 3238-50.

77. Guella I, McKenzie MB, Evans DM, et al. De novo mutations in YWHAG cause early-onset epilepsy. Am J Hum Genet 2017; 101: 300-10.

78. Epi4K Consortium. De novo mutations in SLC1A2 and CACNA1A are important causes of epileptic encephalopathies. Am J Hum Genet 2016; 99: 287-98.

79. Colin E, Daniel J, Ziegler A, et al. Biallelic variants in UBA5 reveal that disruption of the ufm1 cascade can result in early-onset encephalopathy. Am J Hum Genet 2016; 99: 695-703.

80. Muona M, Ishimura R, Laari A, et al. Biallelic variants in UBA5 link dysfunctional UFM1 ubiquitin-like modifier pathway to severe infantile-onset encephalopathy. Am J Hum Genet 2016; 99: 683-94.

81. Arnadottir GA, Jensson BO, Marelsson SE, et al. Compound heterozygous mutations in UBA5 causing early-onset epileptic encephalopathy in two sisters. BMC Med Genet 2017; 18: 103.

82. Palmer EE, Jarrett KE, Sachdev RK, et al. Neuronal deficiency of ARV1 causes an autosomal recessive epileptic encephalopathy. Hum Mol Genet 2016; 25: 3042-54.

83. Tohyama J, Nakashima M, Nabatame S, et al. SPTAN1 encephalopathy: distinct phenotypes and genotypes. J Hum Genet 2015; 60: 167-73.

84. Syrbe S, Harms FL, Parrini E, et al. Delineating SPTAN1 associated phenotypes: from isolated epilepsy to encephalopathy with progressive brain atrophy. Brain 2017; 140: 2322-36.

85. Simons C, Griffin LB, Helman G, et al. Loss-of-function alanyl-tRNA synthetase mutations cause an autosomal-recessive early-onset epileptic encephalopathy with persistent myelination defect. Am J Hum Genet 2015; 96: 675-81.

86. Nakayama T, Wu J, Galvin-Parton P, et al. Deficient activity of alanyl-tRNA synthetase underlies an autosomal recessive syndrome of progressive microcephaly, hypomyelination, and epileptic encephalopathy. Hum Mutat 2017; 38: 1348-54.

87. Mignot C, Lambert L, Pasquier L, et al. WWOX-related encephalopathies: delineation of the phenotypical spectrum and emerging genotype-phenotype correlation. J Med Genet 2015; 52: 6170.

88. Tabarki B, AlHashem A, AlShahwan S, Alkuraya FS, Gedela S, Zuccoli G. Severe CNS involvement in WWOX mutations: description of five new cases. Am J Med Genet A 2015; 167A: 3209-13.

89. Absoud M, Parr JR, Halliday D, Pretorius P, Zaiwalla Z, Jayawant S. A novel ARX phenotype: rapid neurodegeneration with Ohtahara syndrome and a dyskinetic movement disorder. Dev Med Child Neurol 2010; 52: 305-7.

90. Wallerstein R, Sugalski R, Cohn L, Jawetz R, Friez M. Expansion of the ARX spectrum. Clin Neurol Neurosurg 2008; 110: 631-4. 
91. Guerrini R, Moro F, Kato M, et al. Expansion of the first PolyA tract of ARX causes infantile spasms and status dystonicus. Neurology 2007; 69: 427-33.

92. Poirier K, Eisermann M, Caubel I, et al. Combination of infantile spasms, non-epileptic seizures and complex movement disorder: a new case of ARX-related epilepsy. Epilepsy Res 2008; 80: 2248 .

93. Ananth AL, Robichaux-Viehoever A, Kim YM, et al. Clinical course of six children with GNAO1 mutations causing a severe and distinctive movement disorder. Pediatr Neurol 2016; 59: 81-4.

94. Saitsu H, Fukai R, Ben-Zeev B, et al. Phenotypic spectrum of GNAO1 variants: epileptic encephalopathy to involuntary movements with severe developmental delay. Eur J Hum Genet 2016; 24: 129-34.

95. Danti FR, Galosi S, Romani M, et al. GNAO1 encephalopathy: broadening the phenotype and evaluating treatment and outcome. Neurol Genet 2017; 3: e143.

96. Kulkarni N, Tang S, Bhardwaj R, Bernes S, Grebe TA. Progressive movement disorder in brothers carrying a GNAO1 mutation responsive to deep brain stimulation. J Child Neurol 2016; 31: $211-4$.

97. Syrbe S, Hedrich UBS, Riesch E, et al. De novo loss- or gain-of-function mutations in KCNA2 cause epileptic encephalopathy. Nat Genet 2015; 47: 393-9.

98. Pena SD, Coimbra RL. Ataxia and myoclonic epilepsy due to a heterozygous new mutation in KCNA2: proposal for a new channelopathy. Clin Genet 2015; 87: e1-3.

99. Allou L, Julia S, Amsallem D, et al. Rett-like phenotypes: expanding the genetic heterogeneity to the KCNA2 gene and first familial case of CDKL5-related disease. Clin Genet 2017; 9: 431-40. 100. Abdelhadi O, Iancu D, Stanescu H, Kleta R, Bockenhauer D. EAST syndrome: clinical, pathophysiological, and genetic aspects of mutations in KCNJ10. Rare Dis 2016; 4: e1195043. 101. Cross JH, Arora R, Heckemann RA, et al. Neurological features of epilepsy, ataxia, sensorineural deafness, tubulopathy syndrome. Dev Med Child Neurol 2013; 55: 846-56.

102. Al Dhaibani MA, El-Hattab AW, Holroyd KB, et al. Novel mutation in the KCNJ10 gene in three siblings with seizures, ataxia and no electrolyte abnormalities. J Neurogenet 2018; 32: 1-5. 103. Huin V, Strubi-Vuillaume I, Dujardin K, et al. Expanding the phenotype of SCA19/22: Parkinsonism, cognitive impairment and epilepsy. Parkinsonism Relat Disord 2017; 45: 85-9. 104. Martin S, Chamberlin A, Shinde DN, et al. De novo variants in GRIA4 lead to intellectual disability with or without seizures and gait abnormalities. Am J Hum Genet 2017; 101: 1013-20.

105. Madeo M, Stewart M, Sun Y, et al. Loss-of-function mutations in FRRS1L lead to an epileptic-dyskinetic encephalopathy. Am J Hum Genet 2016; 98: 1249-55.

106. Carvill GL, McMahon JM, Schneider A, et al. Mutations in the GABA transporter SLC6A1 cause epilepsy with myoclonic-atonic seizures. Am J Hum Genet 2015; 96: 808-15.

107. Gilfillan GD, Selmer KK, Roxrud I, et al. SLC9A6 mutations cause X-linked mental retardation, microcephaly, epilepsy, and ataxia, a phenotype mimicking Angelman syndrome. Am J Hum Genet 2008; 82: 1003-10.

108. Seltzer LE, Paciorkowski AR. Genetic disorders associated with postnatal microcephaly. Am J Med Genet C Semin Med Genet 2014; 166c: 140-55.

109. Bird LM. Angelman syndrome: review of clinical and molecular aspects. Appl Clin Genet 2014; 7: 93-104.

110. Pollack SF, Grocott OR, Parkin KA, Larson AM, Thibert RL. Myoclonus in Angelman syndrome. Epilepsy Behav 2018; 82: 170-4.

111. Hollstein R, Parry DA, Nalbach L, et al. HACE1 deficiency causes an autosomal recessive neurodevelopmental syndrome. J Med Genet 2015; 52: 797-803.

112. Hariharan N, Ravi S, Pradeep BE, et al. A novel loss-of-function mutation in HACE1 is linked to a genetic disorder in a patient from India. Hum Genome Var 2018; 5: 17061.

113. Nakashima M, Takano K, Tsuyusaki Y, et al. WDR45 mutations in three male patients with West syndrome. J Hum Genet 2016; 61: 653-61. 
114. Hayflick SJ, Kruer MC, Gregory A, et al. $\beta$-Propeller protein-associated neurodegeneration: a new X-linked dominant disorder with brain iron accumulation. Brain 2013; 136: 1708-17.

115. Byrne S, Jansen L, JM UK-I, et al. EPG5-related Vici syndrome: a paradigm of neurodevelopmental disorders with defective autophagy. Brain 2016; 139: 765-81.

116. Ebrahimi-Fakhari D, Saffari A, Wahlster L, et al. Congenital disorders of autophagy: an emerging novel class of inborn errors of neuro-metabolism. Brain 2016; 139: 317-37.

117. Köroğlu Ç, Baysal L, Cetinkaya M, Karasoy H, Tolun A. DNAJC6 is responsible for juvenile parkinsonism with phenotypic variability. Parkinsonism Relat Disord 2013; 19: 320-4.

118. Elsayed LE, Drouet V, Usenko T, et al. A novel nonsense mutation in DNAJC6 expands the phenotype of autosomal-recessive juvenile-onset Parkinson's disease. Ann Neurol 2016; 79: 335-7.

119. Olgiati S, Quadri M, Fang M, et al. DNAJC6 Mutations associated with early-onset Parkinson's disease. Ann Neurol 2016; 79: 244-56.

120. Petrovski S, Kury S, Myers CT, et al. Germline de novo mutations in gnb1 cause severe neurodevelopmental disability, hypotonia, and seizures. Am J Hum Genet 2016; 98: 1001-10.

121. Steinrücke S, Lohmann K, Domingo A, et al. Novel GNB1 missense mutation in a patient with generalized dystonia, hypotonia, and intellectual disability. Neurol Genet 2016; 2: e106.

122. Lohmann K, Masuho I, Patil DN, et al. Novel GNB1 mutations disrupt assembly and function

of $\mathrm{G}$ protein heterotrimers and cause global developmental delay in humans. Hum Mol Genet 2017;

26: $1078-86$.

123. Mignot $\mathrm{C}$, von Stülpnagel $\mathrm{C}$, Nava $\mathrm{C}$, et al. Genetic and neurodevelopmental spectrum of SYNGAP1-associated intellectual disability and epilepsy. J Med Genet 2016; 53: 511-22.

124. Bassuk AG, Wallace RH, Buhr A, et al. A homozygous mutation in human PRICKLE1 causes an autosomal-recessive progressive myoclonus epilepsy-ataxia syndrome. Am J Hum Genet 2008;

83: $572-81$.

125. Malek N, Stewart W, Greene J. The progressive myoclonic epilepsies. Pract Neurol 2015; 15: $164-71$.

126. Dibbens L, Schwake M, Saftig P, Rubboli G. SCARB2/LIMP2 deficiency in action myoclonus-renal failure syndrome. Epileptic Disord 2016; 18: 63-72.

127. Dibbens LM, Michelucci R, Gambardella A, et al. SCARB2 mutations in progressive myoclonus epilepsy (PME) without renal failure. Ann Neurol 2009; 66: 532-6.

128. Corbett MA, Schwake M, Bahlo M, et al. A mutation in the Golgi Qb-SNARE gene GOSR2 causes progressive myoclonus epilepsy with early ataxia. Am J Hum Genet 2011; 88: 657-63. 129. Dibbens LM, Rubboli G. GOSR2: a progressive myoclonus epilepsy gene. Epileptic Disord 2016; 18: 111-4.

130. Oliver KL, Franceschetti S, Milligan CJ, et al. Myoclonus epilepsy and ataxia due to KCNC1 mutation: analys is of 20 cases and K(+) channel properties. Ann Neurol 2017; 81: 677-89.

131. Berkovic SF, Andermann F, Carpenter S, Wolfe LS. Progressive myoclonus epilepsies: specific causes and diagnosis. N Engl J Med 1986; 315: 296-305.

132. Volker JM, Dergai M, Abriata LA, et al. Functional assays for the assessment of the pathogenicity of variants of GOSR2, an ER-to-Golgi SNARE involved in progressive myoclonus epilepsies. Dis Model Mech 2017; 10: 1391-8.

133. Temudo T, Ramos E, Dias K, et al. Movement disorders in Rett syndrome: an analysis of 60 patients with detected MECP2 mutation and correlation with mutation type. Mov Disord 2008; 23: 1384-90.

134. Papandreou A, Schneider RB, Augustine EF, et al. Delineation of the movement disorders associated with FOXG1 mutations. Neurology 2016; 86: 1794-800.

135. Seltzer LE, Ma M, Ahmed S, et al. Epilepsy and outcome in FOXG1-related disorders.

Epilepsia 2014; 55: 1292-300.

136. Bahi-Buisson N, Nectoux J, Rosas-Vargas H, et al. Key clinical features to identify girls with CDKL5 mutations. Brain 2008; 131: 2647-61. 
137. Pederick DT, Homan CC, Jaehne EJ, et al. Pcdh19 loss-of-function increases neuronal migration in vitro but is dispensable for brain development in mice. Sci Rep 2016; 6: 26765.

138. Smith L, Singhal N, El Achkar CM, et al. PCDH19-related epilepsy is associated with a broad neurodevelopmental spectrum. Epilepsia 2018; 59: 679-89.

139. Paciorkowski AR, Traylor RN, Rosenfeld JA, et al. MEF2C Haploinsufficiency features consistent hyperkinesis, variable epilepsy, and has a role in dorsal and ventral neuronal developmental pathways. Neurogenetics 2013; 14: 99-111.

140. Leduc MS. Clinical and molecular characterization of de novo loss of function variants in HNRNPU. Am J Med Genet A 2017; 173: 2680-9.

141. Yates TM, Vasudevan PC, Chandler KE, et al. De novo mutations in HNRNPU result in a neurodevelopmental syndrome. Am J Med Genet A 2017; 173: 3003-12.

142. Bramswig NC, Lüdecke HJ, Hamdan FF, et al. Heterozygous HNRNPU variants cause early onset epilepsy and severe intellectual disability. Hum Genet 2017; 136: 821-34.

143. Tabet AC, Leroy C, Dupont $C$, et al. De novo deletion of TBL1XR1 in a child with nonspecific developmental delay supports its implication in intellectual disability. Am J Med Genet A 2014; 164a: 2335-7.

144. Saitsu H, Tohyama J, Walsh T, et al. A girl with West syndrome and autistic features harboring a de novo TBL1XR1 mutation. J Hum Genet 2014; 59: 581-3.

145. Reijnders MRF, Janowski R, Alvi M, et al. PURA syndrome: clinical delineation and genotype-phenotype study in 32 individuals with review of published literature. J Med Genet 2018; 55: $104-13$.

146. Huisman S, Mulder PA, Redeker E, et al. Phenotypes and genotypes in individuals with SMC1A variants. Am J Med Genet A 2017; 173: 2108-25.

147. Jansen S, Kleefstra T, Willemsen $M H$, et al. De novo loss-of-function mutations in X-linked SMC1A cause severe ID and therapy-resistant epilepsy in females: expanding the phenotypic spectrum. Clin Genet 2016; 90: 413-9.

148. Lebrun N, Lebon S, Jeannet PY, Jacquemont S, Billuart P, Bienvenu T. Early-onset encephalopathy with epilepsy associated with a novel splice site mutation in SMC1A. Am J Med Genet A 2015; 167a: 3076-81.

149. Gorman KM, Forman E, Conroy J, et al. Novel SMC1A variant and epilepsy of infancy with migrating focal seizures: expansion of the phenotype. Epilepsia 2017; 58: 1301-2.

150. Symonds JD, Joss S, Metcalfe KA, et al. Heterozygous truncation mutations of the SMC1A gene cause a severe early onset epilepsy with cluster seizures in females: detailed phenotyping of 10 new cases. Epilepsia 2017; 58: 565-75.

151. Grozeva D, Carss K, Spasic-Boskovic O, et al. De novo loss-of-function mutations in SETD5, encoding a methyltransferase in a 3p25 microdeletion syndrome critical region, cause intellectual disability. Am J Hum Genet 2014; 94: 618-24.

152. Allou L, Julia S, Amsallem D, El Chehadeh S, Lambert L, Thevenon J. Rett-like phenotypes: expanding the genetic heterogeneity to the KCNA2 gene and first familial case of CDKL5-related disease. Clin Genet 2017; 91: 431-40.

153. Zerem A, Haginoya K, Lev D, et al. The molecular and phenotypic spectrum of IQSEC2related epilepsy. Epilepsia 2016; 57: 1858-69.

154. Ewans LJ, Field M, Zhu Y, et al. Gonadal mosaicism of a novel IQSEC2 variant causing female limited intellectual disability and epilepsy. Eur J Hum Genet 2017; 25: 763-7.

155. Assoum M, Philippe $C$, Isidor $B$, et al. Autosomal-recessive mutations in AP3B2, adaptorrelated protein complex 3 beta 2 subunit, cause an early-onset epileptic encephalopathy with optic atrophy. Am J Hum Genet 2016; 99: 1368-76.

156. Tsuchida N, Nakashima M, Miyauchi A, et al. Novel biallelic SZT2 mutations in 3 cases of early-onset epileptic encephalopathy. Clin Genet 2018; 93: 266-74.

157. Venkatesan C, Angle B, Millichap JJ. Early-life epileptic encephalopathy secondary to SZT2 pathogenic recessive variants. Epileptic Disord 2016; 18: 195-200. 
158. Peng M, Yin N, Li MO. SZT2 dictates GATOR control of mTORC1 signalling. Nature 2017; 543: 433-7.

159. Saxena A, Sampson JR. Phenotypes associated with inherited and developmental somatic mutations in genes encoding mTOR pathway components. Semin Cell Dev Biol 2014; 36: 140-6. 160. Paciorkowski AR, McDaniel SS, Jansen LA, et al. Novel mutations in ATP1A3 associated with catastrophic early life epilepsy, episodic prolonged apnea, and postnatal microcephaly. Epilepsia 2015; 56: 422-30.

161. Erro R, Bhatia KP, Espay AJ, Striano P. The epileptic and nonepileptic spectrum of paroxysmal dyskinesias: xhannelopathies, synaptopathies, and transportopathies. Mov Disord 2017; 32: $310-8$.

162. Chen WJ, Lin $Y$, Xiong ZQ, et al. Exome sequencing identifies truncating mutations in PRRT2 that cause paroxysmal kinesigenic dyskinesia. Nat Genet $2011 ; 43$ : 1252-5.

163. Ebrahimi-Fakhari D, Saffari A, Westenberger A, Klein C. The evolving spectrum of PRRT2associated paroxysmal diseases. Brain 2015; 138: 3476-95.

164. Brockmann K, Dumitrescu AM, Best TT, Hanefeld F, Refetoff S. X-linked paroxysmal dyskinesia and severe global retardation caused by defective MCT8 gene. J Neurol 2005; 252: 6636.

165. Tonduti D, Vanderver A, Berardinelli A, et al. MCT8 deficiency: extrapyramidal symptoms and delayed myelination as prominent features. J Child Neurol 2013; 28: 795-800.

166. Jiang YL, Yuan F, Yang Y, Sun XL, Song L, Jiang W. CHRNA4 variant causes paroxysmal kinesigenic dyskinesia and genetic epilepsy with febrile seizures plus? Seizure 2018; 56: 88-91.

167. Damaj L, Lupien-Meilleur A, Lortie A, et al. CACNA1A haploinsufficiency causes cognitive impairment, autism and epileptic encephalopathy with mild cerebellar symptoms. Eur J Hum Genet 2015; 23: 1505-12.

168. Tabarki B, AlMajhad N, AlHashem A, Shaheen R, Alkuraya FS. Homozygous KCNMA1 mutation as a cause of cerebellar atrophy, developmental delay and seizures. Hum Genet 2016; 135: 1295-8.

169. Yeşil G, Aralaşmak A, Akyüz E, İçağasığlu D, Uygur Şahin T, Bayram Y. Expanding the phenotype of homozygous KCNMA1 mutations; dyskinesia, epilepsy, intellectual disability, cerebellar and corticospinal tract atrophy. Balkan Med J 2018: 35: 336-9.

170. Zhang ZB, Tian MQ, Gao K, Jiang YW, Wu Y. De novo KCNMA1 mutations in children with early-onset paroxysmal dyskinesia and developmental delay. Mov Disord 2015; 30: 1290-2.

171. Prontera $P$, Sarchielli $P$, Caproni $S$, et al. Epilepsy in hemiplegic migraine: genetic mutations and clinical implications. Cephalalgia 2018; 38: 361-73.

172. Eunson LH, Rea R, Zuberi SM, et al. Clinical, genetic, and expression studies of mutations in the potassium channel gene KCNA1 reveal new phenotypic variability. Ann Neurol 2000; 48: 64756.

173. Yin XM, Lin JH, Cao L, et al. Familial paroxysmal kinesigenic dyskinesia is associated with mutations in the KCNA1 gene. Hum Mol Genet 2018; 27: 625-37.

174. Choi KD, Choi JH. Episodic ataxias: clinical and genetic features. J Mov Disord 2016; 9: 12935.

175. Sweney MT, Newcomb TM, Swoboda KJ. The expanding spectrum of neurological phenotypes in children with ATP1A3 mutations, alternating hemiplegia of childhood, rapid-onset dystonia-Parkinsonism, CAPOS and beyond. Pediatr Neurol 2015; 52: 56-64.

176. Dale RC, Grattan-Smith $P$, Nicholson M, Peters GB. Microdeletions detected using chromosome microarray in children with suspected genetic movement disorders: a single-centre study. Dev Med Child Neurol 2012; 54: 618-23.

177. Haskell GT, Adams MC, Fan Z, et al. Diagnostic utility of exome sequencing in the evaluation of neuromuscular disorders. Neurol Genet 2018; 4: e212.

178. van Nimwegen KJ, Schieving JH, Willemsen MA, et al. The diagnostic pathway in complex paediatric neurology: a cost analysis. Eur J Paediatr Neurol 2015; 19: 233-9. 
179. Paudel R, Li A, Wiethoff S, et al. Neuropathology of Beta-propeller protein associated neurodegeneration (BPAN): a new tauopathy. Acta Neuropathol Commun 2015; 3: 39.

180. Devinsky O, Cross JH, Wright S. Trial of cannabidiol for drug-resistant seizures in the Dravet syndrome. N Engl J Med 2017; 377: 699-700.

181. Ehinger Y, Matagne V, Villard L, Roux JC. Rett syndrome from bench to bedside: recent advances. F1000Res 2018; 7: 398.

182. Schulz A, Ajayi T, Specchio N, et al. Study of intraventricular cerliponase alfa for CLN2 disease. N Engl J Med 2018; 378: 1898-907. 


\section{[FIGURE LEGENDS]}

Figure 1: Pathophysiology of genetic epilepsy-dyskinesia phenotypes. The genetic epilepsydyskinesia spectrum is associated with mutations in genes encoding proteins with a wide variety of cellular functions (Table S1). Mutations in these genes lead to dysregulation of multiple key cellular processes and neuronal dysfunction, that ultimately manifests clinically as epilepsy and motor deficits. Pathways and processes involved include: gene transcription, posttranslational protein modification, autophagy, ubiquitin-mediated proteolysis, endosomal function, axon myelination, the synaptic vesicle cycle, ion and/or nutrient transport, receptor function, and postsynaptic signal transduction. ADP, adenosine diphosphate; ATP, adenosine triphosphate; $\mathrm{Ca}++$, calcium; DAT, dopamine transporter; $\mathrm{H}+$, hydrogen ion; $\mathrm{K}+$, potassium; $\mathrm{Na}+$, sodium; GDP, guanosine diphosphate; Glu, glucose; GTP, guanosine triphosphate; P, phosphate; RBC, red blood cell; T3, triiodothyronine; $\alpha, \beta, \gamma$, alpha, beta, and gamma subunits of guanine nucleotide-binding proteins $(\mathrm{G}$ proteins). 
Table 1: Summary of clinical manifestations in epilepsy-paroxysmal dyskinesias disorders

\begin{tabular}{|c|c|c|c|c|c|c|c|c|c|c|c|c|c|c|c|c|c|}
\hline Gene & 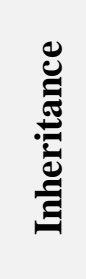 & $\tilde{0}$ & 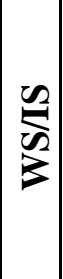 & $\sum_{==1}^{\infty}$ & 空 & 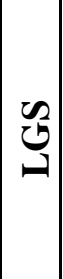 & Other seizure types & 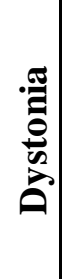 & 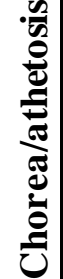 & 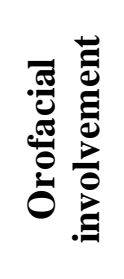 & 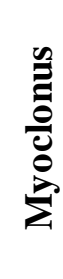 & 萢 & 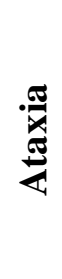 & & 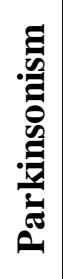 & $\begin{array}{c}\text { Paroxysmal movement } \\
\text { disorders }\end{array}$ & Other key phe notypic features \\
\hline$\overline{A T P 1 A 2}$ & $\mathrm{AD}$ & - & - & - & - & - & Generalized, febrile, GEFS+ & - & - & - & - & - & + & - & - & HM & - \\
\hline$\overline{A T P 1 A 3}$ & $\mathrm{AD}$ & - & - & - & + & - & $\begin{array}{l}\text { GTCS, tonic, atonic, focal with } \\
\text { impaired awareness, myoclonic, } \\
\text { EOEE, status epilepticus }\end{array}$ & + & + & + & - & - & + & - & + & $\begin{array}{c}\text { AHC, rapid-onset } \\
\text { dystonia-parkinsonism, EA }\end{array}$ & CAPOS syndrome \\
\hline $\begin{array}{c}\overline{C A C N A 1} \\
A\end{array}$ & $\mathrm{AD}$ & - & + & - & + & + & $\begin{array}{l}\text { Febrile, GEFS+, absence, } \\
\text { generalized, focal, status } \\
\text { epilepticus, posttraumatic }\end{array}$ & + & + & - & - & - & + & + & - & $\begin{array}{c}\text { PNKD, EA, } \\
\text { HM, benign paroxysmal } \\
\text { torticollis }\end{array}$ & $\begin{array}{l}\text { Cerebellar atrophy, ASD features, } \\
\text { nystagmus }\end{array}$ \\
\hline CHRNA4 & $\mathrm{AD}$ & - & - & - & - & - & $\begin{array}{l}\text { Febrile, GEFS+, myoclonic, } \\
\text { GTCS }\end{array}$ & + & + & - & - & - & - & - & - & PKD & - \\
\hline KCNAI & $\mathrm{AD}$ & - & - & - & - & - & GTCS, focal & + & + & - & - & - & + & - & - & $\begin{array}{l}\text { EA, PKD, myokymia, } \\
\text { neuromyotonia }\end{array}$ & Migraine, vertigo, dysarthria, weakness \\
\hline KCNMA1 & $\mathrm{AD}$ & - & - & - & - & - & Absence, GTCS, clonic, atonic & + & + & - & - & - & - & + & - & PNKD & Cerebellar and corticospinal tract atrophy \\
\hline PRRT2 & $\mathrm{AD}$ & - & - & - & - & - & BFIS & + & + & - & - & - & - & - & - & $\begin{array}{l}\text { PKD, PNKD, PED, EA, } \\
\text { benign paroxysmal } \\
\text { torticollis, HM }\end{array}$ & $\begin{array}{l}\text { Response to low dose antiepileptic } \\
\text { medications }\end{array}$ \\
\hline$\overline{S L C 16 A 2}$ & $\mathrm{X}$ & - & - & - & - & - & Febrile, myoclonic, GTCS & + & - & + & + & + & + & - & - & PKD & $\begin{array}{l}\text { Male predominance, myopathic face, } \\
\text { dysmorphic features, high free T3, normal } \\
\text { low free T4, high TSH }\end{array}$ \\
\hline
\end{tabular}

Causative genes are listed in alphabetical order. SCN1A, SCN8A, and SLC2A1-related phenotypes are also associated with paroxysmal movements, as already detailed in Table SI (online supporting information). OS, Ohtahara syndrome; WS, West syndrome; IS, infantile spasms; EIMFS, epilepsy of infancy with migrating focal seizures; EOEE, early-onset epileptic encephalopathy; LGS, Lennox-Gastaut syndrome; AD, autosomal dominant, GEFS+, generalized epilepsy with febrile seizures plus; HM, hemiplegic migraine; GTCS, generalized tonic-clonic seizures; AHC, alternating hemiplegia of childhood; EA, episodic ataxia; CAPOS, cerebellar ataxia, areflexia, pes cavus, optic atrophy and sensorineural hearing loss; PNKD, paroxysmal non-kinesigenic dyskinesia; ASD, autistic spectrum disorder; PKD, paroxysmal kinesigenic dyskinesia; BFIS, benign familial infantile seizures; PED, paroxysmal exercise-induced dyskinesia; T3, triiodothyronine; T4, thyroxine; TSH, thyroid-stimulating hormone. 